\title{
Nourishing Our Understanding of Role Modeling to Improve Support and Health (NOURISH): Design and Methods
}

\author{
Suzanne E. Mazzeo a,b, Nichole R. Kellya ${ }^{a}$ Marilyn Stern ${ }^{a, b}$, Rachel W. Gow ${ }^{a}$, Kasey Serdar ${ }^{a}$, \\ Ronald K. Evans ${ }^{c}$, Resa M. Jones ${ }^{d}$, and Cynthia M. Bulik \\ aDepartment of Psychology, Virginia Commonwealth University, Richmond, VA \\ bDepartment of Pediatrics, Virginia Commonwealth University, Richmond, VA \\ 'Department of Health and Human Performance, Virginia Commonwealth University, Richmond, \\ VA \\ ${ }^{d}$ Department of Epidemiology and Community Health, School of Medicine, \& Massey Cancer \\ Center, Virginia Commonwealth University, Richmond, VA \\ eDepartment of Psychiatry, University of North Carolina at Chapel Hill, CB 7160, Chapel Hill, NC \\ 27599
}

\begin{abstract}
Pediatric overweight is associated with numerous physical and psychological health risks, and overweight children are at significant risk for obesity in adulthood. African-American children are at particularly high risk for obesity and related health complications. However, this racial group has traditionally had limited access to obesity treatment and relatively few studies have included sufficient numbers of lower-SES, African American participants. Further, although parental involvement in treatment for pediatric overweight has been found to be beneficial, few studies have examined the efficacy of offering treatment exclusively to parents, a potentially costeffective approach which could benefit the entire family. This pilot project will evaluate the efficacy of an intensive parenting intervention, (NOURISH; $\underline{\text { Nourishing }}$ Our $\underline{\text { Understanding of }}$ $\underline{\boldsymbol{R}}$ ole modeling to $\underline{\mathbf{I}}$ mprove $\underline{\boldsymbol{S}}$ upport and $\underline{\boldsymbol{H}}$ ealth), targeting racially diverse parents of overweight children (ages 6-11). NOURISH addresses several urgent research priorities by targeting the underserved and addressing the significant disparity in obesity treatment services. Parents meeting study criteria (having a child between the ages of 6 and 11 with a BMI $\geq$ the $85^{\text {th }}$ percentile) will be offered participation in the randomized trial comparing NOURISH with a control group. We hypothesize that children whose parents participate in NOURISH will manifest greater decreases in BMI, and greater improvements in dietary intake, and quality of life compared to children whose parents do not participate. This study is designed explicitly to gather preliminary feasibility, acceptability, and effectiveness data to inform a subsequent larger randomized controlled trial.
\end{abstract}

\section{Keywords}

obesity; children; African American; treatment; parent; randomized clinical trial

\footnotetext{
(C) 2011 Elsevier Inc. All rights reserved.

Designated Author for Correspondence: Suzanne Mazzeo, Ph.D., Virginia Commonwealth University, White House, 806 West Franklin St., P.O. Box 842018, Richmond, Virginia 23284-2018, 804.827.1708, semazzeo@ vcu.edu.

Publisher's Disclaimer: This is a PDF file of an unedited manuscript that has been accepted for publication. As a service to our customers we are providing this early version of the manuscript. The manuscript will undergo copyediting, typesetting, and review of the resulting proof before it is published in its final citable form. Please note that during the production process errors may be discovered which could affect the content, and all legal disclaimers that apply to the journal pertain.
} 


\section{Introduction}

\subsection{Targeting Parents is Essential in Pediatric Obesity Treatment}

Including parents in pediatric obesity treatment is essential for multiple reasons. First, overweight children commonly have overweight parents $(9,10)$. Moreover, parents serve as powerful models of eating and exercise habits (11-14), and parents' feeding behaviors greatly influence their children's eating and weight (15-18). Further, parental involvement in pediatric obesity treatment is positively associated with child outcomes (19-22). Based on these data, Golan and colleagues (23-25) recommend that parents be the exclusive focus of pediatric obesity treatment. These authors posit that focusing primarily on the child can negatively impact his/her self-esteem and lead to increases in disordered eating (25). In contrast, a parent-only approach prevents the overweight child from being the "identified patient" (23-25). Moreover, a primary focus on parents can facilitate positive change in an entire family's health behaviors. A parent intervention is thus likely to have greater public health benefits than a child-only treatment by reaching entire families. Finally, parent-only interventions are more cost-effective than family-based approaches, as they require fewer staff and other resources (26). Thus, parent-only interventions are more easily translated into real-world settings.

Despite these potential benefits of parent-only interventions for pediatric obesity, this approach remains infrequently used. The earliest research investigating this approach was conducted in Israel, by Golan and colleagues $(23,24)$ who found that children (ages 6-11) of parents in a parent-only intervention lost more weight than children in the standard childfocused treatment. Adherence to the parent-only program was also higher (24) and weight loss was maintained at seven-year follow-up (23). More recently, in the United States, Janicke et al. $(26,27)$ evaluated a parent-only intervention targeting overweight children (age 8-14) in rural settings; participants were primarily White. At post-testing, children of parents in the parent-only condition showed greater decreases in BMI than those in a familybased condition. Adherence was also better in the parent-only condition, and parents in this group reported more satisfaction with the intervention. These authors also found that the parent-only group was more cost-effective (28).

In a related study, conducted in the United States (in Minnesota and California) Boutelle and colleagues (29) conducted a randomized trial in which families with overweight children (ages 8-12) were assigned to either a parent-only or parent and child condition. The conditions yielded similar results with respect to child weight loss and child physical activity. These authors tentatively concluded that parent-only groups are a feasible and effective approach to treat pediatric obesity. However, it should be noted that, in contrast to Janicke et al.'s studies $(26,27)$, Boutelle et al. (29) found that attrition was higher in the parent-only condition. These investigators also had a relatively high rate of attrition overall (30\% in the parent and child group and $40 \%$ in the parent-only group). Thus, they concluded parent-only approaches are promising and potentially cost-effective methods for pediatric obesity treatment; however, more research is needed to support their effectiveness.

Although all of these studies $(23,24,26,27,29)$ provide support for the feasibility, utility and cost-effectiveness of a parent-only approach to treating childhood obesity, they involved relatively small $(23,24,26,27,29)$ and ethnically homogeneous samples $(23,24,26,27)$. Of note, the ethnic/racial composition of Boutelle et al.'s sample is not reported (29); however, more than $60 \%$ of their participants had annual family incomes above $\$ 60,000$; thus, their sample is relatively affluent. Overall, it is unclear whether these results would generalize to low income, ethnically and racially diverse children living in urban areas of the 
United States. Thus additional studies are needed to address the needs of these children, a group especially vulnerable to obesity.

\subsection{African Americans: A Group At-Risk}

Although rates of pediatric overweight have increased in both genders and across ethnic groups, African American children are at particularly high risk (5, 7, 30-32). Further, rates of overweight have increased dramatically within the overall African American population (30). According to the most recent NHANES data (4), rates of overweight and obesity are highest among African American women. Further, obesity-related comorbidities are more common in African American adults compared with Whites (7, 8). Longitudinal research suggests that overweight African American children were more likely to become obese adults than were children of other ethnicities (33).

Given these racial disparities in overweight and obesity, several professional groups, (e.g., NHLBI $(34,35)$ have recommended that the cultural sensitivity of interventions be enhanced for African Americans and other racially and ethnically diverse groups. Optimizing the cultural sensitivity of interventions is important because food selection, preparation, and the eating process itself (including how and with whom food is eaten) are significantly influenced by cultural factors $(36,37)$. For example, qualitative research has found that some African Americans are hesitant to make positive changes in their eating behaviors because they want to maintain their connection to African culture (37). Thus, interventions need to be sensitive to this and similar concerns, and highlight the health-promoting aspects of cultural values and customs related to food selection and eating behavior.

The program described in this paper follows these recommendations and also addresses the disparity in the availability of obesity treatment services highlighted by many authors, including Ammerman et al. (38) who noted there are few treatments that target individuals with the greatest need. Rather, most existing treatments are aimed at individuals who have access to individual multidisciplinary services and the means to afford special foods and other exercise equipment. Other ways in which NOURISH is culturally sensitive include its focus on modifying culturally traditional meals, exploring differences in ideal body preferences, promoting participation in convenient, free (or low-cost), and safe activity options, and managing one's social support system social support to optimize behavior change (38).

Moreover, most family-based behavioral and parent-only approaches to pediatric obesity treatment $(19-25,29,39,40)$, have focused on children from intact and/or higher SES families. Some even required both parents to participate. Based on our previous work (41) in which we found a preliminary version of the intervention described here (NOURISH;

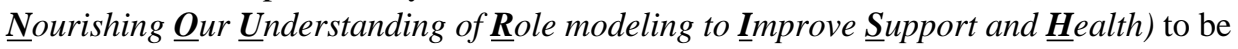
both feasible and acceptable within a predominantly African American sample (total $n=34$ ), we predict that most families in the current trial will be led by a single, female parent. As a result, NOURISH was designed to address potential barriers to health behavior change facing single parent families.

Finally, it is important to note that NOURISH is culturally sensitive, not culturally tailored or exclusive. All participants (regardless of their ethnic/racial background) will be encouraged to consider how cultural factors such as their family-of-origin's values, religion, mealtime and eating traditions, and body image ideals might influence their current behaviors and beliefs regarding these issues. Support for this culturally sensitive approach is provided by previous research investigating the effectiveness of dietary interventions (42), as well as other behavioral change interventions $(43,44)$. Further, our research team has experience conducting group treatments for pediatric obesity with racially, ethnically, and 
socioeconomically diverse families (41). This experience will enable us to achieve our current aims in a culturally sensitive (but not specific) manner. We anticipate that the majority of our sample will be African American (as it has been in previous studies recruited from this same catchment area). We considered making this intervention exclusive to African American families; however we decided against this option, as pediatric obesity is a public health concern that spans all racial and ethnic groups (4). NOURISH is applicable to families from all racial/ethnic backgrounds, thereby enhancing its generalizability. Further, given the importance of maintaining positive relationships with community members, we opted against design decisions that would target one racial/ethnic group as such a recruitment tactic could impair these associations with stakeholders. Further,

\section{Specific Aims}

The primary aim of this study is to implement and evaluate the feasibility, acceptability, and preliminary effectiveness of NOURISH, a culturally sensitive, parent-only skills-based group intervention, and a single-session, education-only, control group (parent-only) intervention on overweight children's BMI percentile. The secondary aim of this study is to evaluate the effectiveness of the intervention for improving children's dietary intake, body dissatisfaction, and quality of life. The impact of these two programs on adult participants will also be evaluated, including parental BMI and dietary intake. Parent satisfaction and feedback regarding the NOURISH intervention will also be elicited. The current pilot project is funded by a small grant (R03 HD-056050-01) meant to be conducted with limited resources. Statistical and anecdotal data from this study will be used to inform a larger randomized controlled trial.

\section{Study Design}

\subsection{Overview}

This study sample will include 90 families with a child between the ages of 6 and 11 with a $\mathrm{BMI} \geq$ the 85 th percentile (45). Families will be recruited from the Richmond, Virginia metropolitan area. Participants will be randomly assigned (using a random number generator) to one of two parent-only interventions (see Section 4 for details regarding these interventions). Both interventions will span 12 weeks. Parents (or the primary caregiver) and children from both interventions will complete outcome measures at baseline, post-testing, and six months after program completion. All intervention and assessment efforts will occur at a community-based clinic in a convenient location. The protocol for this study was approved by the governing Institutional Review Board.

\subsection{Inclusion/Exclusion Criteria}

To qualify for participation, parents or caregivers must be at least 18 years of age and have a child between the ages of 6 and 11 with a BMI $\geq$ the 85 th percentile (45). This child must also primarily reside in the participating caregiver's home. Participants need to speak English fluently, and to be able to understand and follow basic instructions and perform simple exercises. Caregivers are ineligible if they are: 1) non-ambulatory, 2) pregnant, 3) or have a medical diagnosis that may be negatively impacted by exercise. Parents whose children have a medical condition or developmental disorder that precludes weight loss using conventional diet and exercise methods are also ineligible.

\subsection{Recruitment and Retention}

Power analyses were conducted to determine the needed sample size to assess the main study outcome (child BMI percentile). At a two-sided 5.0\% significance level (alpha $=$ 0.05), a sample of 45 individuals per condition (NOURISH or control) would have sufficient 
power to detect a mean BMI percentile difference of 1.0 between groups at a power level of .80 if the true difference between conditions is 2.3 times the standard deviation and a 2.0 percentile difference with .80 power if the true difference between conditions is 2.1 times the standard deviation. Thus, a total of approximately 90 families will be involved in this parenting intervention (divided randomly into the treatment and control groups). Given our experience with recruitment and retention in other clinical trials, we will recruit 60 individuals per condition so that we will have sufficient power with $20 \%$ attrition. It is expected that approximately $70 \%$ of participating families will be African American. One or both parents/caregivers can participate in the intervention program. However, to enhance continuity of treatment dosage within each intervention group, at least one parent will be required to attend the program consistently. All eligible children within individual families will be permitted to participate. Children will not be directly involved in any component of either intervention. However, child care will be available on site for families who need this service to attend program-related activities.

Recruitment will begin several months prior to initiation of the interventions, and will occur continuously until three waves of groups are completed. Once approximately 30 eligible families are identified, the first round of interventions will be scheduled. Future eligible families will be scheduled for the next available group in waves of approximately 30 . Four metropolitan-area school districts will facilitate recruitment of families in local elementary schools. These districts include large percentages of African American and economically disadvantaged students. In particular, $90.1 \%$ of students in the Richmond City school district are African American and $76.6 \%$ receive free or reduced price meals (http://www.richmond.k12.va.us/indexnew/sub/statistics/ethnicstats06_07.cfm). We will also work closely with specific schools in the greater Richmond area with large African American enrollments to inform parents about our program through outreach events (e.g., school health fairs, etc.). Recruitment flyers will also be placed in the front offices of each school. Information regarding this study will be sent to local pediatricians, family practice physicians, and parenting groups for direct referral purposes. This type of personal referral to an intervention by a trusted professional enhances the likelihood of program enrollment $(46,47)$. Further, we will advertise our program to churches and community centers that serve a predominantly African American population (e.g., the Boys and Girls Club). We will also advertise in local parenting publications and on relevant websites, including university list serves. Interested families will be invited to learn more about the study by calling our facilities. All eligibility criteria will be assessed over the phone. If families meet study criteria, they will be invited to an in-person session during which they will complete all baseline measures (immediately after which participants will be randomly assigned to conditions). Each wave will include 30 families, 15 of whom will be randomly assigned to the intervention group, and 15 to the control group. If families are ineligible, appropriate referrals will be made.

To enhance program retention, the interventions will be implemented within the city limits at a site accessible to the bus line and several highways. In addition, several means of contacting participants (e.g., multiple phone numbers, mailing addresses, and email) will be gathered in an attempt to reduce attrition due to lost to follow-up. We will also provide incentives to participants. Specifically, parents and children in both the intervention and control groups will receive a pedometer. Intervention parents will also receive a raffle ticket at each session for a $\$ 75$ gift card which will take place at the final session; thus, participants who attend more sessions have a greater chance of winning the final raffle. Moreover, participants who attend the final session will be given Certificates of Completion. All parents (i.e., intervention and control groups) will be given $\$ 20$ gift cards for completing the pretest, post-test and the six-month follow-up. Further, we will provide childcare for all program sessions and assessments. Multiple follow-up calls will be 
conducted after each missed session, and make-up sessions will be scheduled as needed. Home visits will be conducted to complete assessments if families simply cannot return to our study site to complete assessments.

\subsection{Outcome Measures}

The measures described here will be completed at baseline, post-testing, and six-month follow-up. Prior to any data collection, a detailed consent process will be conducted with each child and parent/caregiver to explain study requirements.

\section{Parent Measures}

Three Factor Eating Questionnaire (TFEQ): The restraint and disinhibition subscales of the TFEQ $(48,49)$ will be used to assess parents' eating behaviors. Content, construct, and criterion-related validity of the TFEQ are established, and the restraint and disinhibition subscales yield internally consistent scores $(48,49)$.

Child Feeding Questionnaire. (CFQ): Parental approaches to and attitudes about feeding their children will be measured by the Child Feeding Questionnaire. The CFQ has yielded reliable and valid scores in samples of parents with elementary age children (50).

Anthropometric measures: Height will be measured to the nearest $1 / 4$ inch using a stadiometer. Weight will be measured to the nearest $1 / 4 \mathrm{lb}$. using a medical balance beam scale. These data will be used to calculate BMI. Abdominal (level of the umbilicus), hip (maximum girth of the hips, above the gluteal fold), and waist (narrowest part of the torso above the umbilicus and below the xiphoid process) circumferences will be assessed using an anthropometric measuring tape, and these data will be used to calculate waist-hip ratio. Percent body fat will be determined by bioelectrical impedance analysis.

Physical Activity: Physical activity will be assessed using the International Physical Activity Questionnaire, Short, Last 7 Days, Self-Administered Format. (IPAQ). The IPAQ is recommended for monitoring levels of physical activity levels for participants ages 18-69, and has been found to manifest adequate reliability and criterion validity (51).

Block Food Screener: Dietary intake will be assessed using the Block Food Screener. This instrument has been validated against the Block 100-item FFQ, which has been found to be an accurate tool for measuring dietary intake in adult populations (52). Correlations between the short fat and fruit/vegetable screener and the longer Block FFQ are 0.69 for total fat (grams/day) and 0.71 for total fruit/vegetable (servings/day; (52).

24-Hour Food Record: Parents will be trained in advance (during their scheduling interview) to complete a 24-hour dietary record. Specifically, each parent will be mailed a food record form to track foods and beverages consumed, portion sizes, time of day consumed and any details on food preparation for a designated 24-hour period. At their assessment appointment, trained psychology graduate students will interview parents to review what they have consumed over the 24-hour period, how foods were prepared, and an estimate of the portion size. Foods then will be analyzed using the Nutrition Data System Software (NDS-R; $(53,54)$. This interactive software package includes interviewer prompts regarding brand names, serving sizes, and cooking methods. Food models will be used to assist parents in reporting portion sizes. The NDS-R provides data organized by food group servings, calories, and nutrient content such as fat, protein, carbohydrates and essential vitamins and nutrients. 
Parent Satisfaction Survey: At the end of the final session, participants will complete an exit questionnaire which assesses: what they liked and disliked about the intervention, thoughts about the duration, frequency, and number of sessions, perceived benefits and barriers to implementing the intervention goals, comfort with group leaders and members, overall satisfaction, and suggestions for improvement.

\section{Child Measures}

24-Hour Food Record: Parents will be trained in advance to complete a 24-hour dietary record for their children, using the methodology described above (Parent Measures). For young children, parent report of intake is more valid than self-report and demonstrates convergence with observational methods of diet (55).

Anthropometric Measures: Height will be measured to the nearest $1 / 4$ inch using a stadiometer. Weight will be measured to the nearest $1 / 4 \mathrm{lb}$. using a balance beam scale. These data will be used to calculate BMI, which will be plotted on the CDC Growth Charts (45) to obtain BMI percentile for age and gender. Circumference measures will be made at the hip, waist, and umbilicus. Abdominal (level of the umbilicus), hip (maximum girth of the hips, above the gluteal fold), and waist (narrowest part of the torso above the umbilicus and below the xiphoid process) circumferences will be assessed using an anthropometric measuring tape, and these data will be used to calculate waist-hip ratio. Percent body fat will be determined by bioelectrical impedance analysis.

\section{Items on the following measures will be read to children by a doctoral student in psychology}

Pediatric Health-Related Quality of Life (PedsQL4.0): The PedsQL (56, 57) has been widely used with children and adolescents with chronic illnesses and assesses perceptions of how health affects daily life in four areas: physical, emotional, social, and school. Internal consistency of this measure is high, and it discriminates effectively between healthy children and children with health problems $(56,57)$.

Pubertal Status: Children (eight years or older) will complete a self-assessment of pubertal status using a pictorial measure (58). This measure was significantly associated with results of physical examinations and is recommended for use in studies where clinical examinations are not feasible (58). For children under eight years of age, we will ask parents to report children's pubertal status.

Figure Rating Scale (FRS): Children's body image will be assessed using the FRS (59). It includes nine figures ranging from underweight to overweight. Children are asked to choose their current and ideal figure; this measure has strong psychometric support (59).

Body-Esteem Scale (BES): The BES assesses children's affective evaluation of their bodies (60). The BES has been used effectively with children as young as five years of age (61).

\section{Interventions}

\subsection{NOURISH Intervention}

NOURISH is based in Social Cognitive Theory (SCT; (62), and emphasizes parental role modeling as a primary way children learn health behaviors. Further, NOURISH focuses on enhancing parents' self-efficacy to make positive changes in eating and exercise behaviors. In addition, cognitive-behavioral strategies such as self-monitoring, contingency management, and stimulus control are incorporated into NOURISH. Further, all sessions will involve participatory activities, including self-assessments, group discussions, and 
experiential activities. These participatory experiences should enhance overall intervention efficacy $(63,64)$. The intervention is also informed by Stages of Change Theory (65). This approach is integrated into the intervention through regular self-assessment of barriers to change as well as moderated discussions on the process (pros and cons) of engaging in a healthier lifestyle. We will also focus on the parents' relationship with everyone in the family, not just the "identified patient" or overweight child, as is recommended by Golan and colleagues $(23,25)$.

Sessions will occur weekly for 12 weeks. Each session will be 90 minutes in duration, and we estimate that there will be approximately 15 parents in each group. Homework will be assigned between sessions to encourage participants to practice the skills learned (64). Participants will also be invited to a one-hour booster session approximately two months after the intervention ends. This session will allow parents to share with one another their successes, and to elicit suggestions from group leaders and fellow parents regarding barriers they have encountered. Treatment manuals, including weekly handouts highlighting session activities, were developed by the research team. The following table briefly outlines the topics covered over the course of 12 weeks.

All sessions will be led by doctoral students in psychology working under the supervision of a licensed, clinical psychologist with specific training in group facilitation. Sessions will be video recorded to allow the investigators to monitor treatment fidelity. Interventionists will meet weekly with the principal investigator for supervision. These meetings will be used to review interventionists' adherence to the treatment protocol, to review program retention, and to discuss participant interactions.

\subsection{Control Group}

Parents in the control group will attend a group session moderated by an independent interventionist (a doctoral student in psychology). This interventionist will be blinded to the aims and hypotheses of this study. The session will address the role of diet and exercise in pediatric overweight. In addition, control parents will receive pedometers (and instructions on their use) for themselves and their children. Control participants will be mailed publicly available brochures on pediatric overweight on three occasions during the study: between weeks four and five, between weeks eight and nine, and two months after post-testing (the latter of which is meant to match the NOURISH booster session).

\section{Statistical Analyses}

The primary and secondary aims of this study will be evaluated using a series of repeated measures analyses of covariance (ANCOVAs), controlling for the influence of pretest scores and other potential covariates, such as pubertal status. ANCOVA is a particularly useful statistical technique for studies using a pretest-posttest design with random assignment, because it enhances statistical power by reducing error variance (70). In these analyses, time (of assessment) will be the within-subjects variable, and group (intervention vs. control) will be the between-subjects variable. Outcomes will be the children's scores at post-testing and 6-month follow-up. Outcome measures will be transformed if they do not meet the assumptions of normality. The impact of these interventions on parental BMI and dietary intake at post-testing and 6-month follow-up will be evaluated using the same ANCOVA procedures.

All analyses will be conducted using an intent-to-treat (ITT) approach. This approach analyzes all the data according to participants' assigned group, whether or not they actually complete the intervention (71). As is recommended, we will use participants' most recent data as post-intervention scores (72). Thus, if participants drop out before completing the 
post-intervention assessment, their baseline scores will be "brought forward" and included in the analyses. This approach protects against validity threats posed by attrition (72). To determine whether rates of attrition differ by treatment condition and more specifically if there is an association between treatment condition and attrition, chi-square analyses will be conducted. Analyses will also include number of sessions attended (i.e., dosage) as a potential effect modifier, or covariate.

\section{Data Management and Safety Monitoring Plan}

Data will be double-entered by the project coordinator and a research assistant with extensive experience in database management. Participants will be assigned a code number, which will be used, instead of names, to maintain confidentiality. Only study staff will have access to identifiable information, and they will be required to complete Health Insurance Portability and Accountability Act (HIPAA) training. In addition, all study staff will be required to complete the Collaborative Investigator Training Initiative (CITI) course in human subjects' protection. All data will be collected and maintained in accordance with these legal and ethical standards. The database will be password-protected, regularly backed up, and maintained on a secure server behind a firewall.

An independent Data and Safety Monitoring Board (DSMB) will be responsible for monitoring the safety of the data obtained in this proposed series of studies. The DSMB will meet regularly, have access to all protocol data, and will have the authority to inquire into protocol process and to suspend or terminate a protocol. They will also ensure that the study is being conducted according to protocol specifications. The DSMB will receive copies of all reportable adverse events. Any adverse events will be reported to the Institutional Review Board (IRB), as well as to the funding source. In accordance with the Office of Research Subjects Protection reporting requirements, any serious, unexpected, related, or possibly related adverse events will be reported to the IRB in writing within two business days of occurrence. The DSMRB will prepare reports of all adverse events and distribute them to the IRB.

\section{Discussion}

In contrast to previous research in the field, NOURISH addresses several urgent research priorities by targeting the underserved and addressing the significant disparity in obesity treatment services. African-American children are at particularly high risk for overweight and its related health complications (3-5). However, this ethnic group has traditionally had limited access to obesity treatment (38) and relatively few studies have included sufficient numbers of lower-SES, African American participants. Further, although parental involvement in treatment for pediatric overweight has been found to be beneficial (19-22), few studies have examined the efficacy of offering treatment exclusively to parents, a potentially cost-effective approach which could benefit the entire family (28).

Although this innovative project has important translational implications, there are several potential challenges involved in its implementation. In particular, recruitment and retention might pose challenges, especially given the high proportion of low-income and single-parent families in our target group. To address these challenges and enhance recruitment efforts, we have made connections with the school systems in our catchment area. The retention rate in our previous pediatric obesity work (73) was relatively high, particularly given the SES and ethnic composition of the sample. We will also attempt to enhance both recruitment and retention by providing incentives, as noted in Section 3.3. 
Another potential challenge is that parents might resist participating in an intervention when they perceive that their child is the one with the clinical concern. It will be especially important to avoid any implicit or explicit message that this parent-only group is addressing deficiencies in their child-rearing approach. Rather, we will emphasize supporting parents, encouraging them to support one another, and highlight the many challenges associated with raising healthy children in what is often considered a "toxic" food environment (74). There will be a major focus on communicating this information empathically, rather than in a pedantic manner, and reiterate our scientific rationale for using this parent-exclusive approach.

Determining the appropriate length of treatment is also a challenge in this study, as in all community-based research (27). We have proposed a 12-week intervention. Although the problem of pediatric obesity involves numerous behavioral and environmental aspects that could be addressed in greater depth in a longer trial, we are attempting to balance treatment intensity with participant burden and feasibility. To evaluate the feasibility and acceptability of this treatment dosage for our target group, we will carefully track attrition over the first few waves of intervention. This length is also consistent with that of related randomized clinical trials (27).

Attention effects and contamination between treatment and control groups are other potential threats to the internal validity of this study. The NOURISH group will have more face-to-face contact with clinicians compared with the control group. We considered an alternative control group matched on attention. However, parents are contacting our research team because they have concerns about their children's weight. Thus, a non-weight-oriented intervention (e.g., safety, first aid), does not seem appropriate. Second, there is no "standardof-care" parent-only treatment that addresses pediatric obesity and could serve as a control group. Third, this was a pilot study; thus, resources (staff, time, etc.) were limited. We anticipate matching therapist contact between conditions more thoroughly in a larger, subsequent RCT.

Further, although contamination between groups is certainly possible, we are recruiting from four school districts with a total of 125 elementary schools. Moreover, the greater metropolitan area in which this study will occur has a population of over one million (75); thus, it is relatively unlikely that participants will know one another. To reduce the risk of contamination further, several precautions will be in place, including randomizing participants to condition after completion of baseline measures and conducting all group meetings and post and follow-up assessments separately by condition; thus members of the treatment and control groups would not be in the clinic at the same time once assigned to their condition. A final limitation of this study is the relatively short follow-up period. Should results of this trial prove promising, a larger grant would enhance our ability to follow families over a longer time period to assess families' long-term health behavior changes.

\section{Conclusions}

In sum, pediatric overweight is a significant public health concern, particularly among African Americans. This group is at high risk for obesity-related complications, and has traditionally had limited access to obesity treatment, despite the identified ethnic disparities in overweight prevalence. Moreover, although parental involvement in treatment for pediatric overweight has been found to be beneficial, this component of treatment has not been adequately assessed in samples with large numbers of African Americans. Thus, this proposed project will address the efficacy of a culturally sensitive parenting intervention targeted at ethnically diverse, high-risk children. We hypothesize that participation in the 
parenting intervention will significantly reduce children's BMI percentiles and enhance overall health outcomes in both parents and children. This pilot trial will facilitate the expeditious collection of preliminary data needed to demonstrate the feasibility and utility of this project and justify a larger RCT.

\section{References}

1. Ogden CL, Carroll MD, Curtin LR, McDowell MA, Tabak CJ, Flegal KM. Prevalence of overweight and obesity in the United States, 1999-2004. J Am Med Assoc. 2006; 295:1549-55.

2. Hedley A, Ogden, Johnson C, Carroll M, Curtin L, Flegal KM. Prevalence of overweight and obesity among US children, adolescents, and adults, 1999-2002. J Am Med Assoc. 2004; 291:2847-50.

3. Institute of Medicine. Preventing childhood obesity: Health in the balance. Washington, DC: National Institute of Health; 2004.

4. Ogden CL, Carroll MD, Curtin LR, Lamb MM, Flegal KM. Prevalence of high body mass index in US children and adolescents. J Am Med Assoc. 2010; 303:242-9.

5. Baskin ML, Ahluwalia HK, Resnicow K. Obesity intervention among African American children and adolescents. Pediatric Clinics of North America. 2001; 48(4):1027-39. [PubMed: 11494636]

6. Ogden CL, Flegal KM, Carroll MD, Johnson CL. Prevalence and trends in overweight among US children and adolescents, 1999-2000. J Am Med Assoc. 2002; 288:1728-32.

7. Melnyk MG, Weinstein E. Preventing obesity in black women by targeting adolescents: A literature review. J Am Diet Assoc. 1994; 94:536-41. [PubMed: 8176129]

8. Crawford PB, Story M, Wang MC, Ritchie LD, Sabry ZI. Ethnic issues in the epidemiology of childhood obesity. Pediatric Clinics of North America. 2001; 48(4):855-78. [PubMed: 11494640]

9. Whitaker RC, Wright JA, Pepe MS, Seidel KD, Deitz WH. Predicting obesity in young adulthood from childhood and parental obesity. N Engl J Med. 1997; 337:869-573. [PubMed: 9302300]

10. Locard E, Mamelle N, Billette A, Miginiac M, Munoz F, Rey S. Risk factors of obesity in a five year old population: Parental versus environmental factors. Int J Obes Relat Metab Disord. 1992; 16:721-9. [PubMed: 1330951]

11. Gibson EL, Wardle J, Watts CJ. Fruit and vegetable consumption, nutritional knowledge and beliefs in mothers and children. Appetite. 1998; 31(2):205-28. [PubMed: 9792733]

12. Fisher JO, Mitchell DC, Smiciklas-Wright H, Birch LL. Parental influences on young girls' fruit and vegetable, micronutrient, and fat intakes. J Am Diet Assoc. 2002; 102:58-64. [PubMed: 11794503]

13. Wardle J, Carnell S, Cooke L. Parental control over feeding and children's fruit and vegetable intake: How are they related. J Am Diet Assoc. 2005; 105:227-32. [PubMed: 15668680]

14. Cooke LJ, Wardle J, Gibson EL, Sapochnik M, Sheiham A, Lawson M. Demographic, familial and trait predictors of fruit and vegetable consumption by pre-school children. Public Health Nutr. 2004; 7(2):295-302. [PubMed: 15003137]

15. Fisher JO, Birch LL. Restricting access to foods and children's eating. Appetite. 1999; 32:405-19. [PubMed: 10336797]

16. Fisher JO, Birch LL. Parents' restrictive feeding practices are associated with young girls' negative self-evaluation of eating. J Am Diet Assoc. 2000; 100:1341-6. [PubMed: 11103656]

17. Fisher JO, Birch LL. Eating in the absence of hunger and overweight in girls from 5 to 7 years of age. American Journal of Clinical Nutrition. 2002; 76:226-31. [PubMed: 12081839]

18. Faith MS, Berkowitz RI, Stallings VA, Kerns J, Storey M, Stunkard AJ. Parental feeding attitudes and styles and child body mass index: prospective analysis of a gene-environment interaction. Pediatrics. 2004; 114:e429-e36. [PubMed: 15466068]

19. Epstein LH, Wing RR, Koeske R, Andrasik F, Ossip DJ. Child and parent weight loss in familybased behavioral modification programs. J Consult Clin Psychol. 1981; 49:674-85. [PubMed: 7287977]

20. Epstein LH, Wing RR, Koeske R, Valoski A. Long-term effects of family-based treatment of childhood obesity. J Consult Clin Psychol. 1987; 55:91-5. [PubMed: 3106445] 
21. Epstein LH, Valoski A, Wing RR, McCurley J. Ten-year follow-up of behavioral family-based treatment for obese children. J Am Med Assoc. 1990; 264:2519-23.

22. Epstein LH, Valoski A, Wing RR, McCurley J. Ten year outcomes of behavioral family-based treatment for childhood obesity. Health Psychol. 1994; 13:373-83. [PubMed: 7805631]

23. Golan M, Crow S. Targeting parents exclusively in the treatment of childhood obesity: Long-term results. Obes Res. 2004; 12:357-61. [PubMed: 14981230]

24. Golan M, Fainaru M, Weizman A. Role of behaviour modification in the treatment of childhood obesity with the parents as the exclusive agents of change. Int J Obes. 1998; 22:1217-24.

25. Golan M, Weizman A, Apter A, Fainaru M. Parents as the exclusive agents of change in the treatment of childhood obesity. American Journal of Clinical Nutrition. 1998; 67:1130-5. [PubMed: 9625084]

26. Janicke DM, Sallinen BJ, Perri MG, Lutes LD, Huerta M, Silverstein JH, et al. Comparison of parent-only vs family-based interventions for overweight children in underserved rural settings: outcomes from project STORY. Archives of Pediatrics and Adolescent Medicine. 2008; 162(12): 1119-25. [PubMed: 19047538]

27. Janicke DM, Marciel KK, Ingerski LM, Novoa W, Lowry KW, Sallinen BJ, et al. Impact of psychosocial factors on quality of life in overweight youth. Obesity. 2007; 15(7):1799-807. [PubMed: 17636099]

28. Janicke DM, Sallinen BJ, Perri MG, Lutes LD, Silverstein JH, Brumback B. Comparison of program costs for parent-only and family-based interventions for pediatric obesity in medically underserved rural settings. Journal of Rural Health. 2009; 25(3):326-30. [PubMed: 19566621]

29. Boutelle KN, Cafri G, Crow SJ. Parent-only treatment for childhood obesity: A randomized controlled trial. Obesity. 2011; 19:574-80. [PubMed: 20966907]

30. Hedley AA, Ogden CL, Johnson CL, Carroll MD, Curtin LR, Flegal KM. Prevalence of overweight and obesity among US children, adolescents, and adults, 1999-2002. Jama. 2004 Jun 16; 291(23):2847-50. [PubMed: 15199035]

31. Institute of Medicine. Preventing Childhood Obesity: Health in the Balance. Washington, DC: The National Academies; 2004.

32. Ogden CL, Flegal KM, Carroll MD, Johnson CL. Prevalence and trends in overweight among US children and adolescents, 1999-2000. JAMA. 2002; 288:1728-32. [PubMed: 12365956]

33. Strauss RS, Knight J. Influence of the home environment on the development of obesity in children. Pediatrics. 1999; 103(6):e85. [PubMed: 10353982]

34. Abrams K, Alen LR, Gray J. Disordered eating attitudes and behaviors, psychological adjustment, and ethnic identity: A comparison of Black and White female college students. International Journal of Eating Disorders. 1993; 14(1):49-57. [PubMed: 8339099]

35. Institute NHLaB. Think Tank on enhancing obesity research at the National Heart, Lung, and Blood Institute. Executive Summary. September 19. 2006 Available from: http://www.nhlbi.nih.gov/health/prof/heart/obesity/ob_res_exsum/ob_res_exsum.pdf

36. Airhihenbuwa CO, Kumanyika S, Agurs TD, Lowe A, Saunders D, Morssink CB. Cultural aspects of African American eating patterns. Ethn Health. 1996; 1(3):245-60. [PubMed: 9395569]

37. James DC. Factors influencing food choices, dietary intake, and nutrition-related attitudes among African Americans: application of a culturally sensitive model. Ethn Health. 2004; 9(4):349-67. [PubMed: 15570680]

38. Ammerman A, Leung MM, Cavallo D. Addressing disparities in the obesity epidemic. North Carolina Medical Journal. 2006; 67:301-4. [PubMed: 17066662]

39. Epstein LH, Wing RR, Steranchak L, Dickson B, Michelson J. Comparison of family-based behavior modification and nutrition education for childhood obesity. J Pediatr Psychol. 1980; 5:25-36. [PubMed: 7452420]

40. Epstein LH, Wing RR, Koeske R, Valoski A. Effects of diet plus exercise on weight change in patients and children. J Consult Clin Psychol. 1984; 52:429-37. [PubMed: 6747061]

41. Mazzeo S, Gow R, Stern M, Gerke CK. Developing an intervention for parents of overweight children. International Journal of Child and Adolescent Health. 2008; 1(4):355-63. 
42. Resnicow K, Davis R, Zhang N, Strecher V, Tolsma D, Calvi J, et al. Tailoring a fruit and vegetable intervention on ethnic identity: Results of a randomized study. Health Psychol. 2009; 28(4):394-403. [PubMed: 19594262]

43. Belgrave FZ, Reed MC, Plybon LE, Corneille M. The impact of a culturally enhanced drug prevention program on drug and alcohol refusal efficacy among urban African American girls. J Drug Educ. 2004; 34(3):267-79. [PubMed: 15648887]

44. Griner D, Smith TB. Culturally adapated mental health intervention: A Meta-analytic review. Psychol Psychother Theor Res Pract. 2006; 43:531-48.

45. Kuczamarski R, Ogden C, Guo S, Grummer-Strawn L, Flegal K. 2000 CDC Growth Charts for the United States: Methods and Development. Vital Series and Health Statistics Series. 2002; 11(246): $1-190$.

46. Loftin WA, Barnett SK, Bunn PS, Sullivan P. Recruitment and retention of rural African Americans in diabetes research: Lessons learned. The Diabetes Educator. 2005; 31(2):251-9. [PubMed: 15797854]

47. Kennedy BM, Newton RL Jr, York-Crowe E, Walden HM, Ryan DH, White MA, et al. Recruiting African American girls and parents for a secondary weight gain prevention study. Journal of Cultural Diversity. 2008; 15(4):181-6. [PubMed: 19202720]

48. Stunkard AJ, Messick S. The three-factor eating questionnaire to measure dietary restraint, disinhibition and hunger. Journal of Psychosomatic Research. 1985; 29(1):71-83. [PubMed: 3981480]

49. Stunkard, A.; Messick, S. Eating Inventory Manual. San Antonio: The Psychological Corporation; 1988.

50. Birch LL, Fisher JO, Grimm-Thomas K, Markey CN, Sawyer R, Johnson SL. Confirmatory factor analysis of the Child Feeding Questionnaire: A measure of parental attitudes, beliefs and practices about child feeding and obesity proneness. Appetite. 2001; 36(6):201-10. [PubMed: 11358344]

51. Craig CL, Marshall AL, Sjostrom M, Bauman AE, Booth ML, Ainsworth BE, et al. International physical activity questionnaire: 12-country reliability and validity. Med Sci Sports Exerc. 2003; 35(8):1381-95. [PubMed: 12900694]

52. Block G, Gillespie C, Rosenbaum E, Jenson C. A rapid food screener to assess fat and fruit/ vegetable intake. Am J Prev Med. 2000; 18(4):284-9. [PubMed: 10788730]

53. Feskanich D, Buzzard IM, Welch BT, Asp EH, Dieleman LS, Chong KR, et al. Comparison of a computerized and a manual method of food coding for nutrient intake studies. J Am Diet Assoc. 1988; 88:1263-7. [PubMed: 3171019]

54. Feskanich D, Sielaff BH, Chong KR, Buzzard IM. Computerized collection and analysis of dietary intake information. Computer Methods and Programs in Biomedicine. 1989; 30:47-57. [PubMed: 2582746]

55. Samet, JM.; Alberg, AJ. Surrogate sources of dietary information. In: Willett, W., editor. Nutritional Epidemiology. New York: Oxford University Press; 1998. p. 157-73.

56. Varni JW, Seid M, Kurtin PS. PedsQL 4.0: Reliability and validity of the Pediatric Quality of Life Inventory Version 4.0 generic core scales in healthy and patient populations. Medical Care. 2001; 39:800-12. [PubMed: 11468499]

57. Varni JW, Seid M, Rode CA. The PedsQL-super (TM): Measurement model for the Pediatric Quality of Life Inventory. Medical Care. 1999; 37:126-39. [PubMed: 10024117]

58. Taylor SJ, Whincup PC, Hindmarch PH, Lampe F, Odoki K, Cook DG. Performance of a new pubertal self-assessment questionnaire: A preliminary study. Pediatric and Perinatal Epidemiology. 2001; 15:88-94. [PubMed: 11237120]

59. Pulvers KM, Lee RE, Kaur H, Mayo MS, Fitzgibbon ML, Jeffries SK, et al. Development of a culturally relevant body image instrument among urban African Americans. Obes Res. 2004; 12:1641-51. [PubMed: 15536228]

60. Mendelson B, White D. Relation between body-esteem and self-esteem of obese and normal children. Percept Mot Skills. 1982; 54:899-905. [PubMed: 7099901]

61 . Wood KA. Effects of a media intervention program on body image and eating attitudes among children. J Undergrad Res. 2004; 7:1-6. 
62. Bandura, A. Social foundations of thought and action. A Social Cognitive Theory. Englewood Cliffs, New Jersey: Prentice-Hall; 1986.

63. Neumark-Sztainer D, Sherwood NE, Coller T, Hannan PJ. Primary prevention of disordered eating among preadolescent girls: Feasibility and short-term effect of a community-based intervention. J Am Diet Assoc. 2000; 100:1466-73. [PubMed: 11138438]

64. Stewart DA, Carter JC, Drinkwater J, Hainsworth J, Fairburn CG. Modification of eating attitudes and behavior in adolescent girls: A controlled study. International Journal of Eating Disorders. 2001; 29:107-18. [PubMed: 11429973]

65. Prochaska J, DiClemente CC, Norcross JC. In search of how people change: applications to addictive behaviors. American Psychologist. 1992; 47:1102-14. [PubMed: 1329589]

66. National Heart Lung and Blood Institute. Executive Summary. 2004. Think Tank on enhancing obesity research at the National Heart, Lung, and Blood Institute.

67. Brownell KD, Kelman JH, Stunkard AJ. Treatment of obese children with and without their mothers: Changes in weight and blood pressure. Pediatrics. 1983; 71(4):515-23. [PubMed: 6835735]

68. Israel AC, Solotar LC, Zimand E. An investigation of two parental involvement roles in the treatment of obese children. International Journal of Eating Disorders. 1990; 9:557-64.

69. Israel AC, Stolmaker L, Sharp JP, Silverman WK, Simon LG. An evaluation of two methods of parental involvement in treating obese children. Behav Ther. 1984; 15:266-72.

70. Huck SW, McLean RA. Using a repeated measures ANOVA to analyze the data from a pretestposttest design: A potentially confusing task. Psychol Bull. 1975; 82:511-8.

71. Hulley, SB.; Cummings, SR.; Browner, WS.; Grady, D.; Hearst, N.; Newman, TB. Designing clinical research. 2. New York: Lippincott Williams \& Wilkins; 2001.

72. Spilker, B. Guide to clinical trials. New York, NY: Raven Press, Ltd; 1991.

73. Bean MK, Mazzeo SE, Stern M, Evans RK, Bryan D, Ning Y, et al. Six-month dietary changes in ethnically diverse, obese adolescents participating in a multidisciplinary weight management program. Clin Pediatr. 2011 [Epub ahead of print].

74. Brownell, KD.; Horgen, KB. Food fight: The inside story of the food industry, America's obesity crisis, and what we can do about it. Chicago: McGraw Hill; 2004.

75. Greater Richmond Partnership of Richmond Virginia. Greater Richmond Demographics. Greater Richmond Partnership of Richmond Virginia. June 29. 2007 Available from: http://intranet.grpva.com/intranet/WEB2002/Populationx_r.asp 
Table 1

Outline of NOURISH Session Content

\begin{tabular}{|l|l|}
\hline Session Number & Session Topic \\
\hline Session 1 & Overview of Childhood Eating Problems and Becoming an Empowered Parent \\
\hline Session 2 & The "Toxic Environment": How Can Parents Fight Back? \\
\hline Session 3 & Nutrition, Portion Sizes, Fruits, and Veggies \\
\hline Session 4 & Emotional and Mindful Eating \\
\hline Session 5 & Parenting Styles \\
\hline Session 6 & Helping your Child Develop a Healthy Relationship with Food \\
\hline Session 7 & Increasing Physical Activity \\
\hline Session 8 & Reducing Physical Activity Barriers \\
\hline Session 9 & Promoting a Healthy Body Image \\
\hline Session 10 & Dealing with Teasing \\
\hline Session 11 & Raising a Media-Savvy Child \\
\hline Session 12 & Bringing it all Together \\
\hline
\end{tabular}

